\title{
Tipps und Tricks für die distale Verriegelung von Marknägeln
}

\author{
Dankward Höntzsch
}

Die distale Verriegelung von Marknägeln geht oft leicht von der Hand, trotzdem sehen wir, dass doch Schwierigkeiten bestehen. Vielleicht können ein paar Tipps und Tricks helfen, die Erfolgsrate noch weiter zu verbessern.

1. Bei der distalen Verriegelung von Marknägeln macht es einen Unterschied, wie der Bildwandler (BV) steht ( Abb. 1). Beim „auf den Sender zu“ bildet sich der Bohrer wegen dem divergierenden Strahlengang gegenüber dem Loch relativ verkleinert ab ( $>$ Abb. 1 a) oder umgekehrt bei der Position „auf den Empfänger zu“ relativ vergrößert ab ( $\bullet$ Abb. 1 b). Mit der Version 1

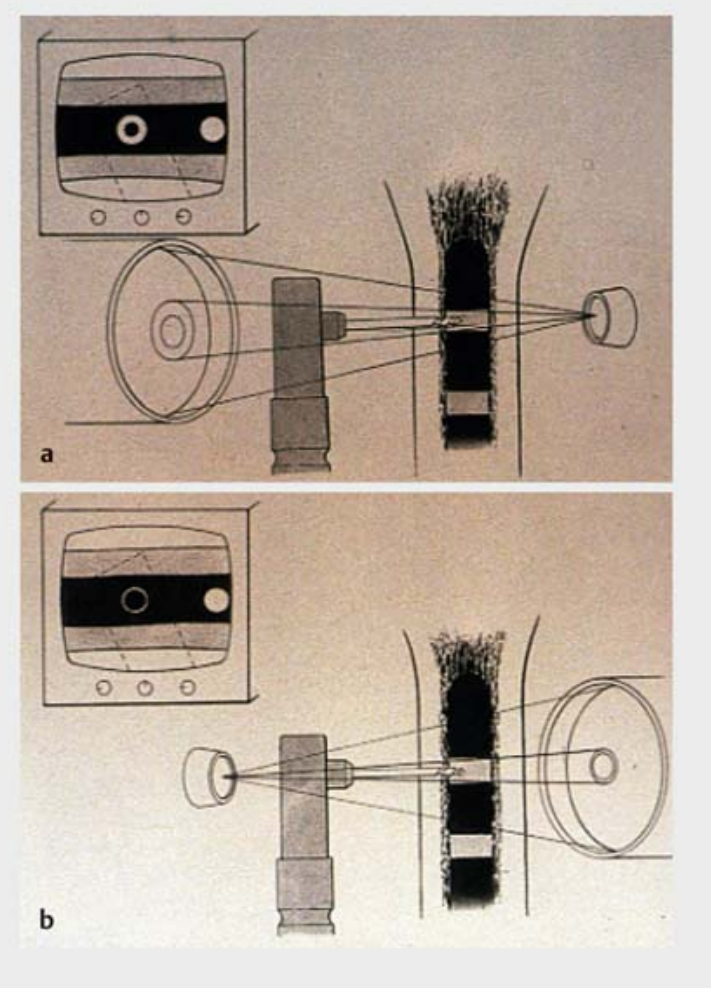

- Abb. 1 Je nach Position der Bildwandlerelemente gibt es eine relative Verkleinerung des Schattens des Bohrers gegenüber dem Schatten des Lochs (a) oder anders herum (b). lässt sich leichter zielen, weil der Schatten des Bohrers verkleinert im Schatten des Verriegelungsloches ist. Der größere Saum erleichtert das Zentrieren.

2. Das BV-Bild muss kongruent zum Operationsfeld sein. Das heißt, rechts muss im Bild rechts sein, genauso muss es mit oben und unten sein ( $\bullet$ Abb. 2 ). Sonst ist die Zielbewegung seitenverkehrt.

3. Der Monitor des Bildwandlers muss geradeaus im Sichtfeld des Operateurs sein, damit man sich nicht auch nur zum Teil umdrehen muss ( $\triangleright$ Abb. 3 ).

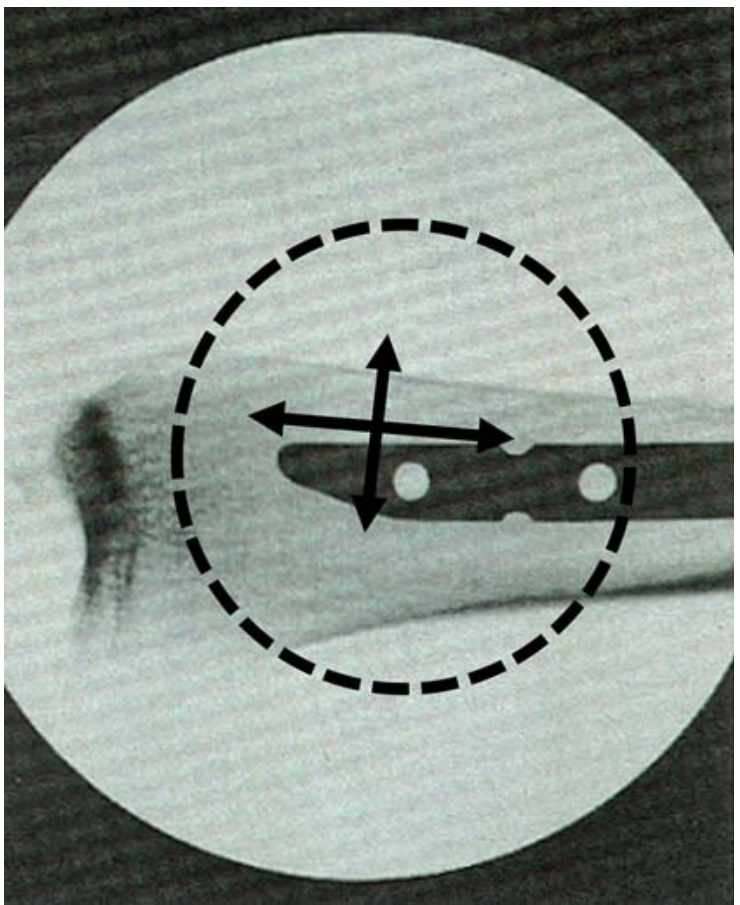

- Abb. 2 Das BV-Bild muss kongruent zum OP-Feld sein. Das Verriegelungsloch muss rund und im Zentrum des BVBildes sein. Sonst kommt es zu Verzerrungen, als ob Kimme und Korn nicht richtig justiert sind, sonst stimmen Zielstrahl und Zielrichtung nicht überein. 


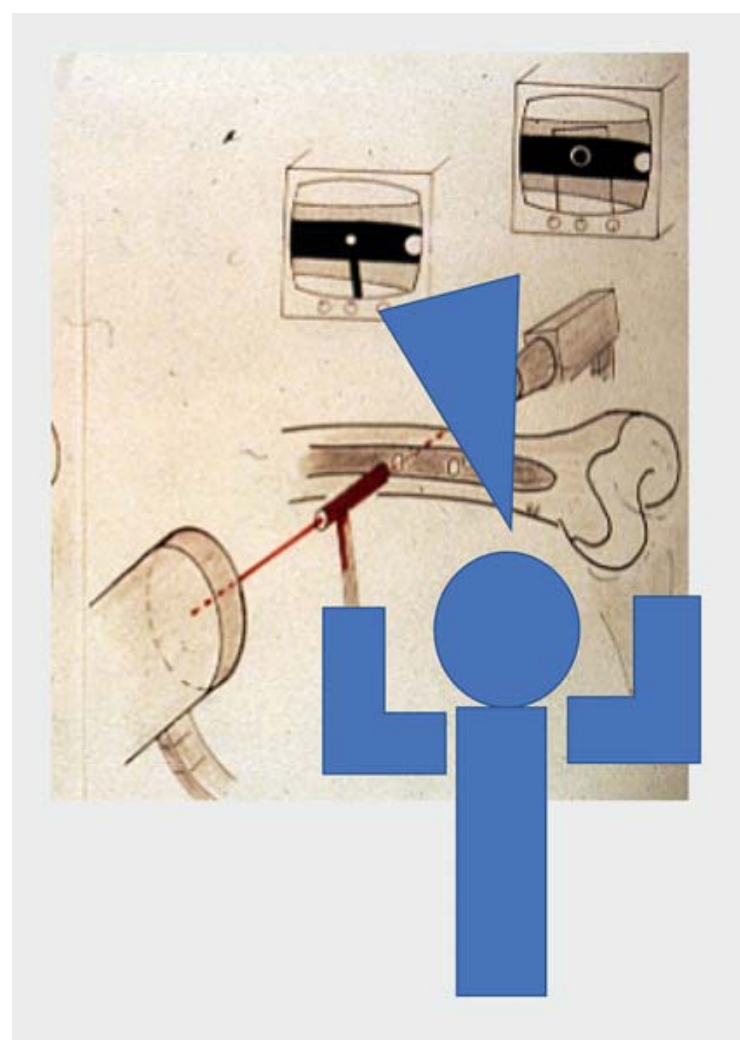

Abb. 3 Beste Position des Monitors des BVs muss in Sichtrichtung sein.
4. Es gibt Übungsmöglichkeiten ( sie.

5. Die Assistenz am Bildwandler muss gut instruiert sein.

6. Das abgebildete Verriegelungsloch muss kreisrund sein und im zentralen Bereich des BV-Bildes sein ( Abb. 2), sonst stimmen Zielstrahl und Zielrichtung nicht überein.

7. Besonders während des Zielens und Bohrens der distalen Verriegelung müssen sich alle konzentrieren.

Viel Erfolg wünscht

D. Höntzsch

Tübingen

Korrespondenzadresse

Prof. Dr. Dankward Höntzsch

hoentzsch@t-online.de

Bibliografie

DOI https://doi.org/10.1055/a-0946-6349

OP-JOURNAL 2019; 35: 190-191 @ Georg Thieme Verlag KC Stuttgart · New York ISSN 0178-1715

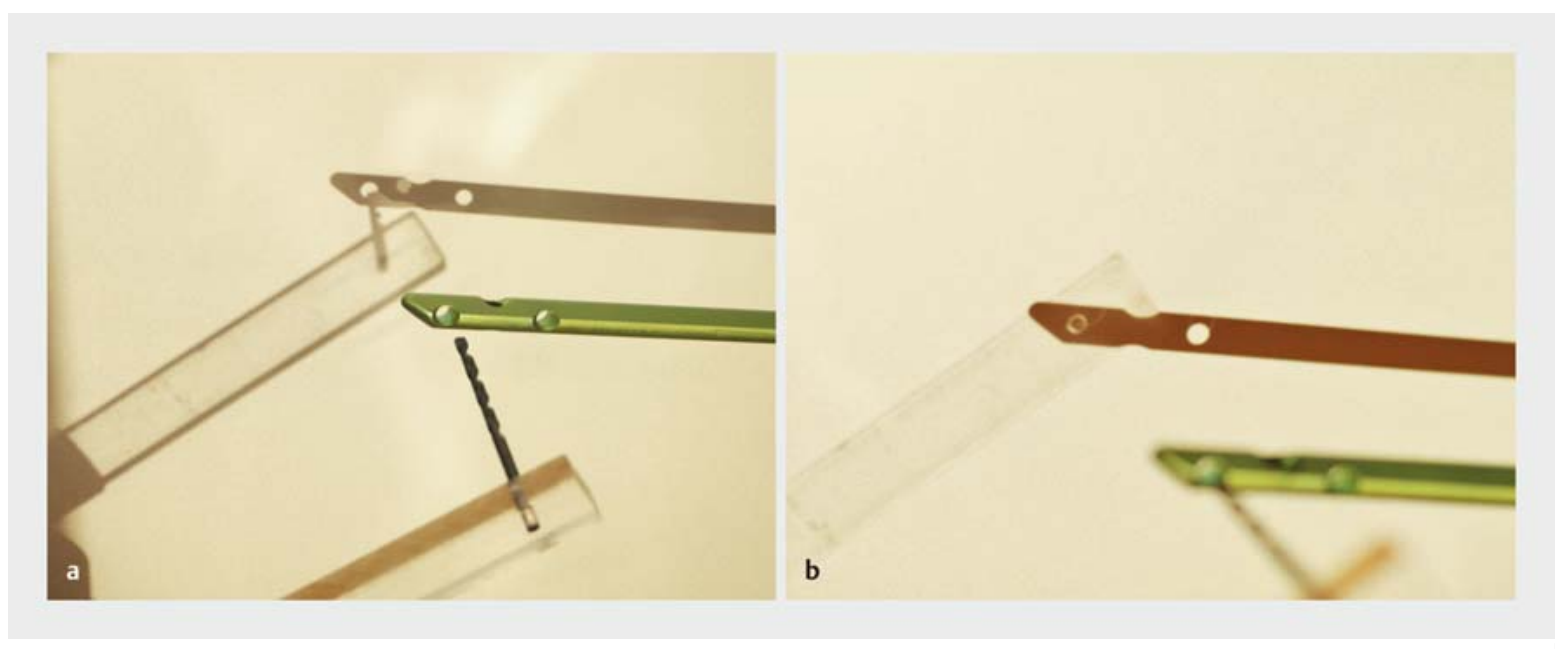

- Abb.4 Ein ganz einfaches Übungsmittel ist ein Bohrer oder einfach nur ein Stab in einem durchsichtigen Plexiglasstab, um mit diesem im Lichtstrahl eines Beamers zu spielen. a aufsetzen, b in den Zentralstrahl einschwenken. 